\title{
Methylmalonic Acid Measurement
}

National Cancer Institute

\section{Source}

National Cancer Institute. Methylmalonic Acid Measurement. NCI Thesaurus. Code C96690.

The determination of the amount of methylmalonic acid present in a sample. 